\section{Use of feed additives for reducing greenhouse gas emissions from dairy farms}

Roonal Pritam Kataria

Jai Hind College, Mumbai, India

Abstract

This review analyses methane emissions from dairy farms due to enteric fermentations and use of different feed additives as a strategy to control them. $\mathrm{CH}_{4}$ is a product that forms during the fermentation of food in the rumen of ruminants and on average represents a 7\% loss of the energy ingested by the animal. $\mathrm{CH}_{4}$ is also a potent greenhouse gas. Various approaches have been studied in many countries with the aim of reducing methane emissions of digestive origin like the use of biotechnologies to modify the microbial ecosystem. This include selection of rumen micro-organisms through the elimination of protozoans or the inoculation of exogenous bacterial strains, vaccination against methanogenic micro-organisms, etc. or use of new food additives like plant extracts, organic acids, etc. and are theoretically promising paths. Their application is however still not known because trials are being performed mainly in vitro. This article focuses on reducing methanogenesis by adjusting the composition of the feed distributed to animals.

\section{Introduction}

Methane is a potent greenhouse gas which absorbs the sun's heat and warms the atmosphere. Thus, if the concentration of heat absorbing gas like methane increases, the atmosphere will warm up resulting in global warming.

The global warming potential (GWP) of methane is 25 times higher than that of $\mathrm{CO}_{2}$, and hence methane significantly contributes to enhanced greenhouse effect. According to NOAA reports in 2011, methane levels rose in 2010 for the fourth consecutive year after remaining nearly constant for the preceding 10 years, up to 1799 parts per billion. Methane concentration was measured 1794 ppb in 2009, and $1714 \mathrm{ppb}$ in $1990 .{ }^{1}$ One of the environmental threats our planet faces today is the potential for long-term changes in the earth's climate and temperature patterns known as global climate change. Average global tempera- tures have risen considerably and the IPCC predicts increases in global average surface temperature tobe $1.8-4^{\circ} \mathrm{C}$ by $2100 .^{2}$ The average arctic temperature in 2012 was about $14.6^{\circ} \mathrm{C}$, which is $0.6^{\circ} \mathrm{C}$ warmer than the mid20 th century baseline. The average global temperature has risen about $0.8^{\circ} \mathrm{C}$ since 1880 , according to the new analysis. ${ }^{3}$ These temperature rises are much greater than those seen during the last century, when average temperature rose only $0.06^{\circ} \mathrm{C}$ per decade. Since the mid-1970s, however, the rate of increase in temperature rise has tripled. ${ }^{4}$ The IPPC's report warns that climate change could lead to impacts on have tremendous impact on environment, animals and humans that are abrupt or irreversible.

\section{Contribution of ruminants to greenhouse gas}

The rising concentration of methane is correlated to increasing populations and currently about $70 \%$ of methane production arises from anthropogenic sources and the remainder from natural sources. Agriculture is considered to be responsible for about two-thirds of the anthropogenic sources. ${ }^{5}$ Biological generation in anaerobic environments (natural and man-made wetlands, enteric fermentation and anaerobic waste processing) is the major source of methane.

Agricultural sources derived from enteric fermentation (81-92 million tonnes), paddy rice production (60-100 million tonnes), biomass burning (40 million tonnes) and animal wastes (25 million tonnes) are the major sources responsible for methane production. ${ }^{6}$ At a global scale, livestock farming contributes to $30-50 \%$ of total greenhouse gas emissions. India has a livestock wealth of 272.1 million cattles, 159.8 million buffaloes, 71.6 million sheep, 140.6 millions goats and 13.1 million other ruminants which produce large amount of methane as a part of their normal digestive process. $^{7}$ this constitutes about $20 \%$ of the world's ruminants population. ${ }^{8}$ Thus, in order to improve the greenhouse gas balance of farming, methane reduction by ruminants is of great concern. It would have a rapid effect on the environment as the life span of methane in atmosphere is 12 years as compared to $100-200$ years of $\mathrm{CO}_{2}$ and $\mathrm{N}_{2} \mathrm{O}$, respectively. ${ }^{9}$ Decreasing methane emissions from these sources by 10 to $15 \%$ would stabilise atmospheric methane at its present level and is a realistic objective. Hence, enormous efforts are being made across the world to find methods that are effective, safe and sustainable. ${ }^{10}$
Correspondence: Roonal Pritam Kataria, Jai Hind College, A Road, backbay Reclamation, Churchgate. Mumbai 400020, India.

Tel.: +91 9664219103

E-mail: rjroonal@gmail.com

Key words: CH4; methanogens; ruminants; energy loss; greenhouse gas; reduction approaches.

Conflcit of interest: the author declares no conflict of interest.

Received for publication: 23 July 2015

Revision received: 11 October 2015.

Accepted for publication: 22 October 2015

This work is licensed under a Creative Commons Attribution NonCommercial 3.0 License (CC BY NC 3.0).

(C) Copyright R.P. Kataria, 2015

Licensee PAGEPress, Italy

Microbiology Research 2015; 6:6120

doi:10.4081/mr.2015.6120

\section{Ruminal fermentation and the production of methane}

Methane is produced as a result of anaerobic fermentation in the rumen and the hindgut. Enzymes present in the rumen hydrolyze the dietary organic matter to aminoacids and simple sugars. The rumen is an ideal habitat for a large and diverse microbial population. ${ }^{11}$ The main functions of this group is to degrade plant polymers which cannot be digested by the host enzymes. The feed material is fermented to volatile fatty acids (VFA), carbon dioxide and methane. These VFAs pass through the rumen wall into the circulatory system and are oxidised in the liver, supplying a major part of the energy needs of the host. Volatile fatty acids may also be directly utilised by the host as building blocks for synthesis of cell material. Fermentation is also coupled to microbial growth and the microbial cell protein synthesised forms the major source of protein for the animal. The gases produced are waste products of the fermentation and are mainly removed from the rumen by eructation. ${ }^{12} \mathrm{~A}$ small proportion of methane is absorbed in the blood and is eliminated through the lungs.

Both methanogenic bacteria and protozoa are involved in methane production in rumen. Virtually all of the bacteria attached to protozoa are methanogens. These bacteria are responsible for between 0.25 and $0.37 \%$ of the total methane produced. Besides protozoa, a number of other organisms are also involved 
in ruminal fermentation and methane production. ${ }^{13}$ Rumen methanogenic archaebacteria utilize hydrogen and carbon dioxide or formate, acetate, methylamine and methanol for production of methane. The involvement of these bacteria in inter-species hydrogen transfer (maintaining low partial pressure of hydrogen within the rumen) is an important interaction which alters the fermentation balance and results in a shift of the overall fermentation from less-reduced to more-reduced endproducts.

\section{Mitigation of methane emis- sions}

Generally speaking, the level of methane production from the rumen is inversely related to the quantity (energy value) and quality (digestibility) of the feed an animal consumes. As the amount of feed consumed increases, the energy available for conversion to methane also increases. There is a relationship between methane emissions and feed digestibility. Therefore, if the effeciency with which the animal digests its feed is increased, the amount of energy released in the form of methane gas by rumen can be reduced. ${ }^{14}$ From about $5-15 \%$ of the digestible energy in feed is lost as methane gas. So, if we could reduce the amount of methane produced by cattle, we could significantly reduce the amount of feed they need and also protect the environment from the hazards of greenhouse effect.

The most promising approach for reducing methane emissions from livestock is by improving the productivity and efficiency of livestock production. Increasing animal productivity will generally reduce methane emissions per $\mathrm{kg}$ of product (milk or meat). Because of the improvement in production effeciency, a greater proportion of the energy in the animal feed is directed towards production of useful products and hence methane emissions per unit product is reduced. This will also lead to a reduction in herd size to produce the given level of product. ${ }^{15}$ In the developed countries of the world, ruminant livestock are kept in well managed production systems and generally fed diets that are very high in digestibility and nutrients. The result is very efficient production (milk or meat) relative to the amount of methane emitted. Unfortunately, ruminants in developing countries are kept on diets that are low in both digestibility and nutrient content. This leads not only to greatly increased methane emissions, but also very diminished productivity relative to the animals' genetic potential. This inefficient productivity has global implications.

However, establishing conditions under which rumen fermentation will be optimised requires an understanding of the nutrient requirements of the mixed microbial population. Growth of rumen microbes is influenced by chemical, physiological and nutritional components. The major chemical and physiological modifiers of rumen fermentation are rumen $\mathrm{pH}$ and turnover rate and both of these are affected by diet and other nutritionally related characteristics such as level of intake, feeding strategies, forage length and quality and forage:concentrate ratios. Recent research has suggested that interventions in early life of the animal can trigger differential microbial rumen colonization and development, which may result in differential rumen $\mathrm{CH}_{4}$ production. This interesting concept may offer new opportunities for mitigating $\mathrm{CH}_{4}$ emission in ruminants but needs to be further tested and verified. ${ }^{16}$ Since methane represents a loss of carbon from the rumen and therefore an unproductive use of dietary energy, scientists have been looking for ways to suppress its production.

\section{Forage selection and processing}

Reduction in methane emissions have been observed through forage selection. The work of McCaughey et al. ${ }^{17}$ have shown that the difference in the carbohydrate fraction of forages such as grass silage, maize silage, legumes or whole crop wheat silage gives rise to difference in productivity. Hence, it is important to select forage species that result in reduced methane production. Grinding and pelleting of forages can markedly decrease methane production. At high intakes methane loss/unit of diet can be reduced $20-40 \%$. Similarly, the work carried out by van Gastelen et al. ${ }^{18}$ show that replacing Grass silage with Corn Silage in a common forage-based diet for dairy cattle offers an effective strategy to decrease enteric $\mathrm{CH}_{4}$ production by $8 \%$ without negatively affecting dairy cow performance. The study undertaken by Lettat et al. ${ }^{19}$ indicated a 13 and $6 \%$ reduction in $\mathrm{CH}_{4}$ per unit of milk out when feeding a 25:75 grass silage:corn silage diet compared with a 75:25 grass silage:corn silage diet. Independent studies carried out by several group of workers demonstrated that comparative high reduction in enteric methane emissions can be achieved by increasing the forage quality combined with the management of stocking rates and rotational grazing strategies. ${ }^{20}$

\section{Nitrates and sulphates}

Both nitrates and sulphates may serve as a terminals electron acceptor and therefore may behave as an alternate hydrogen sink, thereby reducing the amount of methane produced under anaerobic conditions. The nitrate and nitrite along with $\mathrm{CO}_{2}$ are the hydrogen acceptors in the rumen. Conversion of nitrate to nitrite and finally to ammonia is carried out by rumen bacteria.

Leng ${ }^{21}$ provided a comprehensive review of the earlier literature on nitrates. Recent research with sheep and cattle has shown promising results with nitrates decreasing $\mathrm{CH}_{4}$ production by up to $50 \%$. Asanuma et al. ${ }^{22}$ investigated the effects of dietary nitrate addition on ruminal fermentation characteristics and microbial populations in goats. As the result of nitrate feeding, a decrease in the total concentration of ruminal volatile fatty acids and the populations of methanogens, protozoa and fungi was noted. Stoichiometric calculations by Hegarty ${ }^{23}$ show that to reduce methane emissions by $50 \%$, about 0.75 moles of sulphate or nitrate ingestion per day is required. However, since sulphate and nitrate are toxic to ruminants at approximately 0.1 moles/day and 0.25 moles/day respectively, they cannot be fed safely at levels required to reduce methane emission.

\section{Organic acids}

Within the rumen, methane represents a terminal hydrogen sink. Propionate production represents an alternative hydrogen sink in normal rumen fermentation, provided sufficient precursors are available.The main precursors to propionate within this cycle are pyruvate, oxaloacetate, malate, fumarate, and succinate, or alternatively directly from pyruvate to propionate via the acrylate pathway (high concentrate diets). Any of these organic acids may promote alternative metabolic pathways to dispose of reducing power and hence reduce methane production. Existing research shows this to be a very promising approach. Workers in the UK and Spain have studied in vitro the effect of different concentrations of fumarate in the rumen fermentation. ${ }^{24}$

Callaway and Martin ${ }^{25}$ have considered the effect of fumarate and malate on rumen fermentation in vitro. Their results indicated that malate addition not only acted as an alternative hydrogen sink, like fumarate, but also buffers the ruminal contents by a dual mechanism of reducing lactate accumulation and increasing carbon dioxide production. It is essential, particularly with high concentrate diets that the disposal of ruminal lactate is efficient to avoid a severe decline in rumen $\mathrm{pH}$. Martin ${ }^{26}$ found malate and fumarate, as direct metabolic precursors of propionate, reduce methane production when fed in a pure 
form or in high malate forages. It decreases methane emissions by directing hydrogen into succinate rather than into methane. Asanuma et al. ${ }^{27}$ observed that the addition of fumarate to rumen utilizers both hydrogen as well as formate, which are the substrates for the methane formation. Malate has similar effects on fermentation as fumarate..$^{28}$

The option of the use of the organic acids as daily supplements to reduce methane would only be practicably available to livestock receiving supplementary concentrates in a controlled manner. If concentrations of these organic acids in forages could be increased then the option would be available to all ruminant livestock.

\section{Bacteriocins and ionophores}

Bacteriocins are naturally occuring bacterial products with a bacteriocidal activity. They are effective as they directly inhibit methanogens and redirect $\mathrm{H}_{2}$ to other reductive rumen bacteria such as propionate-producer or acetogens. Callaway et al. ${ }^{29}$ have shown that nisin - a food additive, reduces methanogenesis by $36 \%$. However, the organisms developed resistance quickly. This problem can be overcome by the use of bacteriocin of rumen origin. They have a potential as new generation of rumen modifiers. ${ }^{30}$ Lee et al. ${ }^{31}$ found that semipurified bacteriocin i.e. Bovicin HC5 inhibits 50\% of methane production in vitro and methanogens did not show any adaptation to these bacteriocins. Ionophores are antibiotics produced by bacteria. Ionophores increases the proportion of gram positive bacteria in the rumen, resulting in a shift in fermentation acids from acetate and butyrate to propionate, and hence decreases the methane production. ${ }^{32}$ Monensin has been the most studied ionophore and it is routinely used in beef production and more recently in dairy cattle nutrition in many countries. There have been a number of experiments with monensin as a rumen modifier in various production systems, where $\mathrm{CH}_{4}$ production was studied as a main objective either from a mitigation or from an energy loss perspective. ${ }^{33-36}$ Although some studies reported a long-term mitigating effect of monensin on $\mathrm{CH}_{4}$ production, overall the effect of the ionophore on methane production appears to be inconsistent, transient and short-lived indicating that microbial adaptation occurs.

\section{Tannins}

In plants, tannins exist as polyphenols of varying molecular size and complexity and are of two types: hydrolysable and condensed tannins. The condensed tannins also called as proanthocyanidins, has a characteristic influence on proteins and carbohydrates. Tannins have both bacteriocidal and bacteriostatic effect and can also inactivate ruminal enzymes. Tannins supress methanogenesis directly through their antimethanogenic and defaunation property. ${ }^{37}$

Tannins, as feed supplements or as tanniferous plants have a potential for reducing $\mathrm{CH}_{4}$ emission by up to $20 \% .^{38,39}$ Patra et al. ${ }^{40}$ has observed that there is A decrease in vitro metane production with methanol extract of harada (Terminalia chebula) at the level of $0.25 / 30 \mathrm{~mL}$ of incubation medium. He also observed a complete inhibition at double this level. Sources containing both hydrolysable and condensed tannins were shown to be more potent than those containing only hydrolysable tannins. ${ }^{41}$ According to Goel and Makkar, ${ }^{42}$ the antimethanogenic effect of tannins depends on the dietary concentration and is positively related to the number of hydroxyl groups in their structure. These authors concluded that hydrolyzable tannins tend to act by directly inhibiting rumen methanogens whereas the effect of condensed tannins on $\mathrm{CH}_{4}$ production is more through inhibition of fiber digestion.

\section{Saponins}

Saponins are complex compounds that are composed of a saccharide attached to a steroid or triterpene and have a soapy character due to their surfactant properties. Several studies with saponins reported decreased $\mathrm{CH}_{4}$ production from about 6 to $27 \%$ by reducing the protozoa population. ${ }^{42}$ Saponins cause defaunation through their binding with sterols present on the protozoal surface.

Singal et al. ${ }^{43}$ found that 5 herbal products such as pulp powder of reetha (Sapindus mukorossi), shikakai (Acacia concinna), mahua (Madhuca indica) cake, albezia leaves (Albizia lebbek) and yucca (Yucca schiagera) reduces methane production in vitro. Inhibition of methane production upto $96 \%$ was reported with the ethanol and methanol extracts of soap nut (Sapindus mukorossi). ${ }^{44}$ Lila et al..$^{45}$ studied the effect of different concentrations of sarsaponin wherein $60 \%$ of methane reduction was observed as the concentration increased from 1.2 to $3.2 \mathrm{~g} / \mathrm{L}$ fermentation medium.

Studies from China have reported decreased $\mathrm{CH}_{4}$ in ruminants treated with tea triterpenoid saponins but also substantial changes in microbial populations, including a reduction in protozoal counts. ${ }^{46}$ Combination of saponin and nitrate may have practical application in mitigating methane emission from ruminants. In a study, Quillaja saponin and nitrate in combination at low dose inhibited methanogenesis substantially while increasing feed degradability. ${ }^{47}$

\section{Use of probiotics}

Direct-fed microbials (DFM), in one form or another, are commonly used as supplements in animal production. The most widely used microbial feed additives (live cells and growth medium) are based on Saccharomyces cerevisiae (SC) and Aspergillus oryzae (A0). Their effect on rumen fermentation and animal productivity are wide ranging and this has been reviewed by several authors. ${ }^{48,49}$

Work carried out by Chaucheyras et al. ${ }^{50}$ suggest that live yeast cells can stimulate the use of hydrogen by acetogenic strains of ruminal bacteria there by enhancing the formation of acetate and decreasing the formation of methane. However, the effects of yeast are strain dependent. ${ }^{51}$ The other effects observed include shift in fermentation towards butyrate or propionate or reduction in protozoal numbers. These effects are variable and shortterm, diminishing 2-4 hour after feeding. Other DFM interventions of ruminal fermentation include inoculation with lactate-producing and lactate utilizing bacteria to promote more desirable intestinal microflora and stabilize $\mathrm{pH}$ and promote rumen health, respectively. ${ }^{52}$ There have also been other attempts to inoculate the rumen with fungi (Candida kefyr) and lactic acid bacteria (Lactococcus lactis) along with nitrate supplementation to control methanogenesis, but no consistent animal data have been reported. ${ }^{53}$

\section{Use of prebiotics}

The prebiotics or oligosaccharides are non digestible carbohydrates normally used in the non ruminants for better gut health and feed utilization. They are used in rumen manipulation along with nitrates, probiotics and yeast to have reduced methane production. The increase in cellulolytic rumen bacteria is provided by using prebiotic compounds such as mannan-oligosaccharide (MOS), fructooligosaccharide (FOS), galacto-oligosaccharide. ${ }^{54}$ Mwenya et al. ${ }^{55}$ showed that they enhances propionate production by stimulating Selenomonas, Succinomonas and Megasphera with inhibition of acetate producers such as Ruminococcus and Butyrivibrio. The administration of galacto-oligosaccharides have brought about reduction of methane prodution upto $11 \%$. 


\section{Vaccinations}

The work of Baker ${ }^{56}$ have shown that it is possible to immunize ruminants against their own methanogens thereby reducing methane emission. Methanogens are antigenically distinct from other organisms in the rumen; hence a vaccination can help in reduction of methane production by rumen methanogens. A vaccine developed by Wright et al. ${ }^{57}$ containing 3 methanogen mixture produced a $7.7 \%$ reduction in methane emission. However, at present vaccines do not have sufficient efficacy for commercial use.

Vaccines against rumen archaea are based on the concept of a continuous supply of antibodies to the rumen through saliva. Vaccines against archaea have been successful in vitro. ${ }^{58}$

New approaches have involved identification of genes encoding specific membranelocated proteins from Methanobrevibacter ruminantium and using purified proteins (produced in Escherichia coli) as antigens to vaccinate sheep. ${ }^{59}$ The development of vaccines, is an exciting and fast-developing area of research that may produce effective $\mathrm{CH}_{4}$ mitigation technologies in the future. ${ }^{60}$

\section{Fats and oils}

Oils offer a practical approach to reducing methane in situations where animals can be given daily feed supplements, but excess oil is detrimental to fiber digestion and animal production. Both dietary oil and essential oil acts as modifiers of rumen fermentation.

\section{Dietary oils}

Dietary oils like coconut oil, sunflower oil, mustard oil, horseradish oil have been found to reduce methane production in rumen.

Dietary fat seems a promising nutritional alternative to depress ruminal methanogenesis without affecting other ruminal parameters. ${ }^{61}$ Some of the possible mechanisms by which lipid supplementation reduces methane: reducing fiber digestion (mainly in long chain fatty acids); suppression of methanogens and suppression of rumen protozoa ${ }^{62}$ and to a limited extent through biohydrogenation of unsaturated FA thereby serving as a hydrogen sink. ${ }^{63}$

Machmulleur et al. ${ }^{62}$ observed coconut oil as more effective inhibitor followed by rapeseed, sunflower seed, and linseed oil. Coconut oil comprises medium chain fatty acids. Coconut oil control rumen methanogens by changing the metabolic activity and composition. A decrease in protozoa numbers has been as identified as explanation for the reduction in methane emission after the inclusion of coconut oil in the diet. Ruminal ciliate protozoa rely on hydrogen producing fermentation process that is inhibited by a high concentration of hydrogen. They share a symbiotic relationship with ruminal methanogens which allows an interspecies hydrogen transfer, thereby lowering the concentration of hydrogen for the ciliate protozoa. Therefore, less hydrogen is available for formation of methane after defaunation. ${ }^{64}$

Dong et al. ${ }^{65}$ compared canola oil to coconut oil and demonstrated coconut oil as more effective methane inhibitor. Kongmuna et al. ${ }^{66}$ reported that supplementation of coconut with garlic powder improved in vitro ruminal fluid fermentation in terms of the VFA profile, reduced methane losses and reduced protozoal population. The inclusion of sunflower oil to the diet of cattle resulted in $22 \%$ decrease of methane emissions. ${ }^{67}$ The addition of canola oil at $0 \%, 3.5 \%$ or $7 \%$ to the diets of sheep reduced the number of rumen protozoa by $88-97 \%$. 62

However, fats and oils may pose numerous negative impacts to the animals. Dietary oil supplementation caused lower fiber digestibility ${ }^{67}$ Jordan et al. ${ }^{68}$ estimated that feeding copra meal containing coconut oil to animals takes a longer time to reach a common carcass weight and decrease the effects on total methane emissions. Many factors need to be considered such as the type of oil, the form of the oil (whole crushed oilseeds vs. pure oils), and handling issues e.g. coconut oil has a melting point of $25^{\circ} \mathrm{C}$ ). High cost and the negative impact on milk fat concentration are some of the limitations of oil supplementation. Its impact on milk fatty acid composition and overall milk fat content would need to be carefully studied. Recent strategies, based on processed linseed, turned out to be very promising in both respects. ${ }^{61}$

\section{Essential oils}

Essential oils (E0) are blends of secondary metabolites obtained from the plant volatile fraction by steam distillation. They have characteristic aroma or essence. They have a very diverse composition, nature, and activities. The most important active compounds are included in 2 chemical groups: terpenoids (monoterpenoids and sesquiterpenoids) and phenylpropanoids. These 2 groups originate from different precursors of the primary metabolism and are synthesized through separate metabolic pathways. ${ }^{69}$

These compounds are as antiseptics and antimicrobials. Due to the hydrophobic nature of the cyclic hydrocarbons; they interact with cell membranes and accumulate in the lipidic bilayer of bacteria, occupying a space between the chains of fatty acids. This interaction causes conformational changes in the membrane structure, resulting in its fluidification and expansion. The loss of membrane stability results in the leakage of ions across the cell membrane, which causes a decrease in the transmembrane ionic gradient. In most cases, bacteria can counterbalance these effects by using ionic pumps and cell death does not occur, but large amounts of energy are diverted to this function and bacterial growth is slowed down, resulting in changes in the fermentation profile. ${ }^{69}$

Several studies have documented reduction in methane production by EOs. Supplementation of ruminant diets with EOs can alter microbial populations, digestion and fermentation of diets, proteolysis, and methanogenesis in the rumen. ${ }^{69-74}$

In vitro studies demonstrated that garlic oil reduced the emission of $\mathrm{CH}_{4}$. The active diallyldisulfide and allylmercaptan were responsible for most of its effects. According to Ankri and Mirelman ${ }^{74}$ its antimicrobial activity is due to the organo-sulphur compounds, particularly allicin. The anti-methanogenic effect of garlic is due to direct inhibition of Archaea microorganisms in the rumen. Archaea have unique membrane lipids that contain glycerol linked to long-chain isoprenoid alcohols essential for the stability of the cell membrane. The synthesis of the isoprenoid units in methanogenic Archaea is catalyzed by the enzyme hydroxyl methyl glutaryl coenzyme A (HMG-CoA) reductase. Gebhardt and $\mathrm{Beck}^{75}$ found that garlic oil is a strong inhibitor of HMG-CoA reductase and hence the synthesis of the isoprenoid unit is inhibited, the membrane becomes unstable, and the cells die.

Castillejos et al. ${ }^{76}$ reported the effects of Thyme (Thymus spp.) and oregano (Origanum spp.) oils on methane production. The active component thymol is a monoterpene with strong antimicrobial activity against a wide range of gram-positive and negative bacteria. Thymol affects the energy metabolism of 2 relevant rumen bacteria grown in pure culture: Streptococcus bovis and Selenomonas ruminantium. It reduces methane concentrations as well as total volatile fatty acid production due to inhibition of microbial metabolism. It causes loss of integrity of the cell membrane and a reduction in the uptake of glucose. ${ }^{77}$ The effects of thymol are diet and $\mathrm{pH}$ dependent. Therefore, it is important to define the conditions under which these additives are used to modify rumen microbial fermentation in the desired direction. ${ }^{78}$

Five essential oils (EOs), namely, clove oil (CLO), eucalyptus oil (EUO), garlic oil (GA0), origanum oil (ORO), and peppermint oil (PE0), were tested in vitro for their effect on methane production. The CLO contains eugenol (phenyl propanoid), EUO contains cineole (bicyclic monoterpinoid), GAO contains alliin and allicin (organosulfur compounds), ORO contains thymol (monoter- 
pinoid monocyclic phenol), and PEO contains menthol (monoterpinoid monocyclic non phenol). This study demonstrated that all the EOs significantly reduced methane production with increasing doses. However, different EOs vary in their potencies in modulating rumen microbial populations and fermentation. Further, a single EO may not effectively and practically mitigate methane emission from ruminants unless used at low doses in combinations with other antimethanogenic compounds. ${ }^{79}$

\section{Conclusions}

The experimental results obtained with inhibition of methanogenesis in the rumen indicate that there exists a large number of chemicals, bacteriocins, antibiotics and plant secondary compounds like oils, tannins, saponins, etc which have the potential to modify the rumen microbial fermentation. However, each one of them is accompanied with one or the other drawback like simultaneous adverse effect on the other biochemical reactions in the rumen, toxic effect on the health, retention of some of the chemicals in the livestock product, etc.

The rumens microbes specially the methanogens get adapted to some of these feed additives and initial adverse effect observed on inhibition of methanogenesis are lost. In addition to these, most of the feed additives tested in vitro and found effective in inhibiting methanogenesis, have not been tested in vivo and therefore, their exact potential for practical use is still not known.

The use of any method for methane reduction can only be justified if there is a beneficial effect larger than the cost of the product. This ratio will depend on the cost of feed additive, the dose required and the resulting improvement in the animal performance. Generally, the techniques are economically non adaptable due to their high cost and lower performance in the form of methane emission.

The most promising approach is one involving immunization against strains of both rumen protozoa and rumen methanogens, offering up to $70 \%$ reduction in methane emissions. This is at an early stage of development and the longevity of the immunization is required to be established. If successful, this approach could be applied to all ruminants in all member states. The use of propionate precursors and direct fed microbial offer alternative approaches which may allow up to $25 \%$ reductions in methane emissions and would be available to all livestock receiving daily supplements.

In the last two decades a lot of strategies to mitigate methane production in ruminants have been researched upon. There are numer- ous possibilities associated with this and most of which require substantial amounts of research and development so as to apply multiple technologies to mitigate greenhouse gas emission. However, strategies that can succeed at farm level should be more practical and involve no additional inputs. The potential of plant extracts in mitigating methane emission in ruminants is one such strategy that can be readily adopted as an on-farm practice. Since ruminants are so important to mankind as they convert rich fibrous biomass of the world into high quality protein sources i.e. meat and milk for human consumption, more considerations should be given to total farm greenhouse gas emissions, and not just methane emissions from enteric fermentation when investigating the issues.

\section{References}

1. NOAA. Greenhouse gas index continues climbing. 2011. Available from: http://www.noaanews.noaa.gov/stories201 1/20111109_greenhousegasindex.html

2. IPCC. Climate change 2007: the physical science basis summary for policymakers contribution of working group I to the fourth assessment report of the Intergovernmental Panel on Climate Change. 2007. Available from: http://www.ipcc.ch/ipccreports/ar4wg1.html

3. NOAA. Global temperature trends: 2012 summation. 2012. Available from: http://www.arctic.noaa.gov/detect/globaltemps.shtml

4. NOAA. A top ten warm year for U.S. and Globe. United States Department of Commerce. 2007. Available from: http://www.noaanews.noaa.gov/stories200 7/20071213_climateupdate.html

5. Duxbury JM, Mosier AR. Status and issues concerning agricultural emissions of greenhouse gases. In: Kaiser H, Drennen T, eds. Agricultural dimensions of global climate change. Florida; St. Lucie Press; 1993. pp 229-258.

6. Patra AK. Enteric methane mitigation technologies for ruminant livestock: a synthesis of current research and future directions. Environ Monitor Assess 2012;184:1929-2.

7. GOI. 17th Livestock Census 2012. Ministry of Agriculture, Government of India; 2012.

8. Sridhar GT, Rita R, Syma A, et al. Effect of Trigonella foenum-graecum- Brassica juncea on methane production in buffalo and cross breed cattle. Int $\mathrm{J}$ Adv Res 2014;2:1041-7.

9. Bhatta R, Malik PK, Prasad CS, et al. Enteric methane emission: status, mitiga- tion and future challenges: an Indian perspective. Livest Prod Climate Change 2015;229.

10. Grainger C, Beauchemin KA. Can enteric methane emissions from ruminants be lowered without lowering their production? Anim Feed Sci Technol 2011;166167:308-20.

11. Bryant MP. Normal flora-rumen bacteria. Am J Clin Nutr 1970;23:1440-50.

12. Dougherty RW, Mullenaux CM, Allison MJ. Physiology of digestion in the ruminant. In: Dougherty RW, ed. London; Butterworth; 1965. p.159.

13. Vogels GD, Hoppe WF, Stumm CK. Association of methanogenic bacteria with rumen ciliates. Appl Environ Microbiol 1980;40:608-12.

14. Hegarty RS. Strategies for mitigating methane emissions from livestock. Australian options and opportunities. Proceedings of 1st International Conference on Greenhouse Gases and Animal Agriculture. Obihiro, Japan; 2002. pp 61-65.

15. Howden SM, O'Leary GJ. Evaluating options to reduce greenhouse gas emissions from an Australian temperate wheat cropping system. Environmental Software and Modelling 1997;12:169-76.

16. Abecia L, Martin-Garcia AI, Martinez G, et al. Manipulation of the rumen microbial ecosystem to reduce methane emissions in ruminants through the intervention at early life stage of pre-ruminants and their mothers. Adv Anim Biosci 2011;2:271.

17. McCaughey WP, Wittenberg K, Corrigan D. Impact of pasture type on methane production by lactating cows. Can J Anim Sci 1999;79:221-6.

18. van Gastelen S, Antunes-Fernandes EC, Hettinga KA, et al. Enteric methane production, rumen volatile fatty acid concentrations, and milk fatty acid composition in lactating Holstein-Friesian cows fed grass silage-or corn silage-based diets. J Dairy Sci 2015;98:1915-27.

19. Lettat FH, Benchaar C. Corn silage in dairy cow diets to reduce ruminal methanogenesis: effects on the rumen metabolically active microbial communities. J Dairy Sci 2013;96:5237-48.

20. Mirzaei-Aghsaghali A, Maheri-Sis N. Factors affecting mitigation of methane emission from ruminants I: feeding strategies. Asian J Anim Vet Adv 2011;6:888-908.

21. Leng $R$. The potential of feeding nitrate to reduce enteric methane production in ruminants. Canberra, Australia: Commonwealth Government of Australia; 2008.

22. Asanuma N, Yokoyama S, Hino T. Effects of nitrate addition to a diet on fermentation and microbial populations in the rumen of 
goats, with special reference to Selenomonas ruminantium having the ability to reduce nitrate and nitrite. Anim Sci J 2015;86:378-84.

23. Hegarty RS. Mechanisms for competitively reducing ruminal methanogenesis. Aust $\mathrm{J}$ Agric Res 1999;50:1299-305.

24. Wood TA, Wallace RJ, Rowe A, et al. Encapsulated fumaric acid as feed ingredients to decrease ruminal methane emissions. J Anim Feed Sci Technol 2009;152:62-71.

25. Callaway TR, Martin SA. Effects of organic acids and monensin treatment on in vitro mixed ruminal microorganism fermentation of cracked corn. J Anim Sci 1999;74:1982-9.

26. Martin SA. Manipulation of ruminal fermentation with organic acid: a review. J Anim Sci 1998;76:3123-32.

27. Asanuma N, Iwamoto M, Hino T. Effect of addition of fumarate on methane production by ruminal microorganisms in vitro. $\mathrm{J}$ Dairy Sci 1999;82:780-7.

28. Martin C, Morgavi DP, Doreau M. Methane mitigation in ruminants: from microbe to the farm scale. Animal 2010;4:351-65.

29. Callaway TR, Carnerio De Melo AMS, Russell JB. The effect of nisin and monensin on ruminal fermentations in vitro. Curr Microbiol 1997;35:90-6.

30. Teather RM, Forster RJ. Manipulating the rumen microflora with bacteriocins to improve ruminant production. Can J Anim Sci 1998;78:57-69.

31. Lee SS, Hsu JT, Mantovani C, Russell JB. The effect of bovicin HC5, a bacteriocin from Streptococcus bovis HC5, on ruminal methane production in vitro. Microbiol Lett 2002;217:51-5.

32. Schelling GT. Monensin mode of action in the rumen. J Anim Sci 1984;58:1518-27.

33. Sauer FD, Fellner V, Kinsman R, et al. Methane output and lactation response in Holstein cattle with monensin or unsaturated fat. J Anim Sci 1998;76:906-14.

34. Van Vugt SJ, Waghorn GC, Clark DA, Woodward SL. Impact of monensin on methane production and performance of cows fed forage diets. Proc N Z Soc Anim Prod 2005;65:362-6.

35. Waghorn GC, Clark H, Taufa V, Cavanagh A. Monensin controlled-release capsules for methane mitigation in pasture-fed dairy cows. Aust J Exp Agric 2008;48:65-8.

36. Abrar A, Tsukahara T, Kondo M, et al. Effect of monensin withdrawal on rumen fermentation, methanogenesis and microbial populations in cattle. Anim Sci J 2015;86:849-54.

37. Cieslak A, Szumacher-Strabel M, Stochmal A, Oleszek W. Plant components with specific activities against rumen methanogens. Animal 2013;7:253-65.
38. Zhou YY, Mao HL, Jiang F, et al. Inhibition of rumen methanogenesis by tea saponins with reference to fermentation pattern and microbial communities in Hu sheep. Anim Feed Sci Technol 2011;166-167:93100.

39. Staerfl SM, Amelchanka SL, Kalber T, et al. Effect of feeding dried high-sugar ryegrass ('AberMagic') on methane and urinary nitrogen emissions of primiparous cows. Livest Sci 2012;150:293-301.

40. Patra, AK, Kamra DN, Agrawal N. Effect of plant extracts on in vitro methanogenesis enzyme activities and fermentation of feed in the rumen liquor of buffalo. Anim Feed Sci Technol 2006;128:276-91.

41. Tajima K, Takenaka A, Uyeno Y, et al. Influence of the nature of tannins on in vitro methanogenesis, rumen fermentation pattern, methanogenic archaea and protozoa population. Proceedings of International animal Nutrition Conference, National Dairy Research Institute, Karnal. 2007; 2:301.

42. Goel G, Makkar H. Methane mitigation from ruminants using tannins and saponins. Trop Anim Health Prod 2012;44:729-39.

43. Singhal K, Anamika K, Singh B. Effect of saponins of plant extracts on rumen fermentation and methane emission. Proceedings of International animal Nutrition Conference, National Dairy Research Institute, Karnal. 2007; 2:297.

44. Goel G, Makkar HP, Becker K. Changes in microbial community structure, methanogenesis and rumen fermentation in response to saponin-rich fractions from different plant materials. Appl Microbiol 2008;105:770-7.

45. Lila ZA, Mohammed N, Kanda S, et al. Effect of sarsaponin on rumen fermentation with particular reference to methane production in vitro. J Dairy Sci 2003;86:3330-6.

46. Wang J, Ye J, Liu, J. Effects of tea saponins on rumen microbiota, rumen fermentation, methane production and growth performance: a review. Trop Anim Health Prod 2012;44:697-706.

47. Patra AK, Yu Z. Effective reduction of enteric methane production by a combination of nitrate and saponin without adverse effect on feed degradability, fermentation, or bacterial and archaeal communities of the rumen. Bioresour Technol 2013;148:352-60.

48. Martin SA and Nisbet DJ. Effects of direct fed microbials on rumen microbial fermentation. J Diary Sci 1992;75:1736-44.

49. Newbold CJ, Rode LM. Dietary additives to control methanogenesis in the rumen. Inter Cong Ser 2006;1293:138-47.

50. Chaucheyras-Durand F, Durand H.
Probiotics in animal nutrition and health. Benef Microbes 2010;1:3-9.

51. Chung YH, Walker ND, McGinn SM, Beauchemin KA. Differing effects of 2 active dried yeast (Saccharomyces cerevisiae) strains on ruminal acidosis and methane production in non-lactating dairy cows. J Dairy Sci 2011;94:2431-9.

52. Henning $\mathrm{PH}$, Horn $\mathrm{CH}$, Leeuw KJ, et al. Effect of ruminal administration of the lactateutilizing strain Megasphaera elsdenii (Me) NCIMB 41125 on abrupt or gradual transition from forage to concentrate diets. Anim Feed Sci Technol 2010;157:209.

53. Takahashi J. Some prophylactic options to mitigate methane emission from animal agriculture in Japan. Asian-Aust J Anim Sci 2011;24:285-94.

54. Ghosh S, Mehta R. Influence of dietary supplementation of prebiotics (mannanoligosaccharide) on the performance of crossbred calves. Trop Anim Health Prod 2012;44:617-22.

55. Mwenya B, Santoso B, Sar C, et al. Effects of including Beta 1-4, galacto-oligosaccharides, lactic acid bacteria or yeast culture on methanogenesis as well as energy and nitrogen metabolism in sheep. Animal Feed Sci Technol 2004;115:313-26.

56. Baker SK. Methods of improving utilization of nutrients by ruminants or ruminant-like animals. Int. patent W09511041. 1999.

57. Wright AD, Kennedy $\mathrm{P}, \mathrm{O}^{\prime} \mathrm{Neill} \mathrm{CJ}$, et al. Reducing methane emissions in sheep by immunization against rumen methanogens. Vaccine 2004;22:3976-85.

58. Wedlock DN, Pedersen G, Denis M, et al. Development of a vaccine to mitigate greenhouse gas emissions in agriculture; vaccination of sheep with methanogen fractions induces antibodies that block methane production in vitro. $\mathrm{N} \mathrm{Z}$ Vet $\mathrm{J}$ 2010;58:29-36.

59. Buddle BM, Denis M, Attwood GT, et al. Strategies to reduce methane emissions from farmed ruminants grazing on pasture. Vet J 2011;188:11-7.

60. Wright A, Klieve, A. Does the complexity of the rumen microbial ecology preclude methane mitigation? Anim Feed Sci Technol 2011;166-167:248-53.

61. Wanapat M, Kang S, Polyorach S. Development of feeding systems and strategies of supplementation to enhance rumen fermentation and ruminant production in the tropics $\mathrm{J}$ Anim Sci Biotechnol 2013;4:32.

62. Machmuller AD, Ossowski A, Wanner M, Kreuzer M. Potential of various fatty feeds to reduce methane release from rumen fermentation in vitro. Anim Feed Sci Technol 1998;71:117-30. 
63. Manh NS, Wanapat M, Uriyapongson S, et al. Effect of Eucalyptus camaldulensis leaf meal powder on rumen fermentation characteristics in cattle fed on rice straw. Afr J Agri Res 2012;7:1997-2003.

64. Machmuller A, Soliva CR, Kreuzer M. Effect of coconut oil and defaunation treatment on methanogenesis in sheep. Reprod Nutr Dev 2003;43:41-55.

65. Dong Y, Bae HD, McAllister TA, et al. Lipidinduced depression of methane production and digestibility in the artificial rumen system. Can J Anim Sci 1997;77:269-78.

66. Kongmuna P, Wanapat M, Pakdeea P, et al. Manipulation of rumen fermentation and ecology of swamp buffalo by coconut oil and garlic powder supplementation. Livest Sci 2011;135:84-92.

67. McGinn SM, Beauchemin KA, Coates T, Colombatto D. Methane emissions from beef cattle: effects of monensin, sunflower oil, enzymes, yeast and fumaric acid. J Anim Sci 2004;82:3346-56.

68. Jordan E, Lovett DK, Monahan FJ, et al. Effect of refined coconut oil or copra meal on methane output and on intake and performance of beef heifers. J Anim Sci 2006;84:162-70.

69. Patra AK, Saxena J. A new perspective on the use of plant secondary metabolites to inhibit methanogenesis in ruminants. Phytochemistry 2010;71:1198-22.

70. Patra AK. Effects of essential oils on rumen fermentation, microbial ecology and ruminant production. Asian J Anim Vet Adv 2011;6:416-28.

71. Burt S. Essential oils: their antibacterial properties and potential applications in foods: a review. Int J Food Microbiol 2004;94:223-5.

72. Chaves AV, He ML, Yang WZ, et al. Effects of essential oils on proteolytic, deaminative and methanogenic activities of mixed ruminal bacteria. Can J Anim Sci 2008;89:97-104.

73. Agarwal N, Shekhar C, Kumar R, et al. Effect of peppermint (Mentha piperita) oil on in vitro methanogenesis and fermentation of feed with buffalo rumen liquor. Anim Feed Sci Technol 2009;148:321-7.

74. Ankri S, Mirelman D. Antimicrobial prop- erties of allicin from garlic. Microbes Infect 1999;2:125-9.

75. Gebhardt R, Beck H. Differential inhibitory effects of garlic-derived organo-sulfur compounds on cholesterol biosynthesis in primary rat hepatocyte cultures. Lipids 1996;31:1269-76.

76. Castillejos L, Calsamiglia S, Ferret A. Effect of essential oil active compounds on rumen microbial fermentation and nutrient flow in in vitro systems. J Dairy Sci 2006;89:2649-58.

77. Ultee A, Bennik M, Moezelaar R. The phenolic hydroxyl group of carvacrol is essential for action against the food-borne pathogen Bacillus cereus. Appl Environ Microbiol 2002;68:1561-8.

78. Macheboeuf D, Morgavi DP, Papon Y, et al. Dose-response effects of essential oils on in vitro fermentation activity of the rumen microbial population. Anim Feed Sci Technol 2008;145:335-50.

79. Patra A, Yu Z. Effects of essential oils on methane production and fermentation by, and abundance and diversity of, rumen microbial populations. Appl Environ 